\title{
1. Framing the spatial dimension of social imaginaries
}

This book focuses on the spatial dimension of social imaginaries. The guiding hypothesis throughout is that this dimension is constitutive of modern social imaginaries. From an analytical point of view, this book's objective is to show that a full understanding of these imaginaries requires characterizing forms of spatiality at work by differentiating their respective statuses. In order for such a proposition to be fully intelligible, there must first be a clarification of its terms and an introduction of the references it is based on.

\section{BETWEEN IMAGINARY AND IMAGINATION}

The social imaginary concept has held a very special place in social science vocabulary since Cornelius Castoriadis' works in the 1970s. At that time, the concept of the imaginary had already made inroads into the theories of existentialist philosophy with Jean-Paul Sartre (1940) in psychoanalysis, and then either discredited by authors such as Jacques Lacan ([1966] 2006) or overestimated by others such as Gilbert Durand (1960) in this context, and in literary studies, particularly in the Francophone world. Castoriadis' works brought about both an extension and a redirection. He did retain from psychoanalysis the idea that the individual is motivated by an imagining activity that is the particularity of its psyche. He links it to what he calls "the radical imagination." But he is also and above all mindful of understanding the nature of the "social imaginary," that is, the understanding of the world that an individual acquires through exterior social forces. For Castoriadis, this social imaginary emerges in precise historic conditions - it is "instituting" - and is stabilized in an "instituted" form. This tension that puts into play instituted social imaginary, radical imagination as a factor of change, and a new instituting social imaginary as a modality of change enabled him to account for dynamics that make new social realities emerge in a definitely non-deterministic way: "The imaginary of which I am speaking is not an image of. It is the unceasing and essentially undetermined (social-historical and psychical) creation of figures/ forms/images on the basis of which alone there can never be a question of 'something.' What we call 'reality' and 'rationality' are its works" ([1975] 1987, p. 3). The title of Castoriadis' main book on the topic - The Imaginary 
Institution of Society ([1975] 1987) - says it all: the imaginary, in its many specific forms, becomes this activity by which each society, in its own way, institutes itself, in particular through the radical imagination of the individuals who make up this society. Conceiving of the appearance of new social worlds, without a necessarily historical continuity, without postulating the existence of recurrent explicative structures, thus enables him to free himself from the Marxist theory to which he had previously adhered.

This way of conceiving the imaginary as an instituting condition of the social sparked a massive interest in English-speaking authors from the 1990s onwards, for example, Charles Taylor (2004), Michael Warner (2005) and Manfred Steger (2008). This interest followed the English translation of Castoriadis' book in 1987, but also the historic events in Berlin, the USSR and in Latin America that showed that authoritarian regimes can falter and that civil societies assert themselves by manifesting a certain autonomy. Thus, this concept of social imaginary, rather than ideology (in the orthodox Marxist meaning) or even habitus (in Bourdieu's vocabulary) aimed at delimiting this "background" (Taylor) according which human groups reinvent themselves. He also wanted to look into better understanding how these subjectivities, referring to a same background, could adjust to each other and lead to the adoption of common practices.

Charles Taylor's work exemplifies this sense of the social imaginary concept. In Modern Social Imaginaries (2004), Taylor, from a moral and political philosophical perspective, deals with the specificities of Western modernist influence and of the other modernities that have emerged throughout the world under its influence. Taylor grounds these specificities in the idea found in some philosophical works of the seventeenth century, mainly those of John Locke and Hugo Grotius, and circulated all through the following centuries, that modern society would be endowed with a new moral order in which individual interest and collective interest interact around the idea of mutual benefit. He sees in early theories about the market economy, in the constitution of a public sphere and in the setting up of new relations between the state and the individual the main vectors of this emerging order. The social imaginary is the framework or the matrix that gives a collective orientation to all of the social practices and their related significations. It is "what enables, through making sense of, the practices of a society" (Taylor, 2002, p. 91). Or, said otherwise, it is "the kind of common understanding that enables us to carry out the collective practices that make up our social life" (Taylor, 2004, p. 24). Taylor also wants to identify the principles of sociality that are specific to modernity, "the ways people imagine their social existence, how they fit together with others, how things go on between them and their fellows, the expectations that are normally met, and the deeper normative notions and images that underlie these expectations" (Taylor, 2004, p. 23). While he refers to and acknowledges 
Cornelius Castoriadis and his work, he does not mobilize his proposal's psychoanalytical register. Taylor is convinced that the social imaginary is not an attribute of a society but the very condition of its institutionalization. Taylor suggests, in the continuity of his work on the modern meaning of the notion of identity (notably, Taylor, 1989), that social imaginaries not only institute societies but are also constitutive of their collective identity, in particular because they relate to their self-understanding.

\section{A FRAMING PROPOSAL}

This renewed interest for the notion of the imaginary is occurring when some major English-language scholars, such as Edward Said, Benedict Anderson or Arjun Appadurai, have given "imagination" a central place in their analysis. The movement between "imagination" and "imaginary" has partially to do with the subtleties of the linguistic communities at work in the academic world. These two terms have functioned as lexical attractors, the latter within the Francophone and the former within the Anglophone community. The hiatus is particularly perceptible in the translations from one language to the other. ${ }^{1}$ But the reference to imagination sometimes refers to something else, a theoretical perspective or an epistemological position. In his analysis of nations as "imagined communities," Benedict Anderson (1983) posits that nations constituted themselves, in the long term between the sixteenth and the twentieth centuries, thanks to individuals' ability to imagine their inscription in this type of collective as a result of the rise of several types of mediators such as administrative documents, books and newspapers that configured linguistic modalities of distant interaction. As for Arjun Appadurai, in his analysis of the contemporary world that he sees traversed by the flows of people and information, he credits imagination, in other words, individuals' imagining activity. To understand the ongoing manifestations of globalization, he stresses the ways in which individuals' imagination enables each one to position him-/ herself in a group of "landscapes" - cultural, the media, economic, etc. - while generally freeing him-/herself from the framework of nation-states. Moreover, beyond the semantic subtleties that enrich languages and torment translators, Anglophone authors' interest in the concept of imagination takes into account a certain propensity of the individual to want to recognize that the individual has some autonomy in his/her imagining activity, while many Francophone

1 The word imaginary is rarely used in English to designate anything but the counterpoint to real. This explains why the "imaginaire" of French-language writers often becomes "imagination" for English translators: L'Imaginaire médiéval by Jacques Le Goff (1991) was translated the following year as The Medieval Imagination, and L'Imaginaire by Sartre (1940) translated as The Psychology of Imagination in 1948. 
authors were tempted to see in the imaginary either a deterministic framework or the unconscious bases of this activity.

This is the divide of the epistemological positions, expressed in part by lexical preferences, that Castoriadis, Taylor and Warner tried to go beyond in their work. This book also takes inspiration from their ideas. It addresses the social imaginary as a background of thinking and action patterns shared within a collective. It posits that this imaginary is not a simple attribute of a society but the very condition of its existence as such: the imaginary pertains to the institution of a society and therefore frames those social institutions that organize its functioning. This is the framework in which I will discuss the "social imaginary," the "state imaginary" or the "group imaginary." The adjective specifies the corresponding institutionalized collective. I will likewise avoid speaking of the "geographic imaginary," the "territorial imaginary" or the "historical imaginary" because these qualifiers do not designate collectives. Rather, I will deal with the "imaginary of space," the "imaginary of nature," the "imaginary of territory," the "imaginary of landscape" or the "imaginary of time" to say that space, nature, territory, landscape and time are categories of objectification in the process of social institutionalization.

Using this conception of the social imaginary, then, the notion no longer has much in common with its usual meaning. The imaginary is no longer a counterpoint to reality; it becomes a realm to which members of a society explicitly or implicitly bring their understanding of this reality and the modalities of its practice. So as to prevent the social imaginary from being a kind of floating abstraction with a vague status, it has to be attached to concrete practices, including those of individual imagination. And this sense also has to be separated from the usual meaning, which connects it, essentially, to activities like art or dreaming or which boils it down to this ability to summon, by thought processes, an entity that is not in the field of perception, because it is far away, has disappeared or been projected into the future. I propose, in part for reasons that will be explained further on in the book, to consider that imagination mainly designates the imagining activity of an individual that fans out at the intersections between experiences, norms and references; in other words, a quintessential daily activity that gives sense to each one of our practices.

Using this way of seeing the social imaginary and individual imagination as the two sides of one reality, there are several ways of conceiving of the relationship between them. I will not address the theses that say that the social imaginary determines individual imagination. Because if individual imagination were the simple consequence or actualization of a social imaginary, the interest of its analysis would be marginal and the imaginary would only be ideology. Like Appadurai, this book's thesis features individual imagination while recognizing its autonomy and invention. But it will also stress, more than Appadurai does, how a shared imaginary stabilizes individuals' imagining 
activity and then orients it. Between a triumphant instituting imaginary and an individual imagination free from any shackles, this book favours a middle position, hard to maintain. It aims to account for the effects of a social imaginary on how individual practices are carried out but also on the invention potential of individual imaginations, and therefore on how individual imagination can contribute to the transformation or the emergence of a social imaginary. At this point, the proposal can be likened to a postulate. The following chapters want to solidify it.

\section{SPACE AND SOCIAL IMAGINARIES}

I said at the outset: this book focuses on the spatial dimension of social imaginaries and the forms of spatiality at work. What do I mean by forms of spatiality?

One elementary way of accounting for the spatiality of societies is to remember, like Hannah Arendt, that the human condition is fundamentally earthbound, or, as she herself wrote, "the earth is the quintessence of the human condition" (1958, p. 34). No individual experience, no social reality exists independently of the concrete space on which it unfolds. However obvious this is, it often leads to reducing the spatiality of social facts either in the way they mobilize a material space or in their formal expression, by way of a map for example. In both cases, one is tempted to think of social space as a simple translation "in space" of these realities or geographic space as a specific arrangement of human activities "on space" or "in space." This conception of space is endowed with a status of exteriority in relation to these practices and these facts. It is clear that it constitutes a necessary condition but not a veritably constitutive dimension of the social and even less of the social imaginary itself.

Another, surely more ambitious, way of proceeding is to posit that space in all its forms pertains to the very definition of social practices and their signification. Arendt, to stay in her company, also made proposals in this field, in particular using her concept of "space of appearance" (1958), which is defined as an arrangement of individuals in public space, with the special position and point of view (in the literal, phenomenological meaning of the term) that every person adopts and by the speech they utter in interaction. This situated speech for Arendt is constitutive of political action. The "space of appearance" is a decisive modality of what she calls power, as long, of course, as power is not conceived of as a substance but as a practice of interaction in a material context configured in this outlook. Therefore, beyond its materiality and graphic expressions, space would be at work in the institutionalization of the political. It would be both the material condition of possibility and the operating modality of the political. Unlike the first mode, it is as a result of the 
operating modality of the political that that one can say that space is institutive of a political society. As an example, the space of appearance is what makes the political, as Arendt defines it.

There is another form of spatiality that will be addressed here and that Arendt deals with, albeit in a less original way, in two of her works: The Origins of Totalitarianism (1951) and Eichmann in Jerusalem (1963). Statonational territoriality resulted from the rapprochement of state territoriality and national territoriality beginning in the nineteenth century. This double territoriality is also instituting inasmuch as territory is much more than an attribute of the modern state and of the nation. This is the basis on which the modern state was conceived and instituted as of the sixteenth century and on which the basis of the idea of nation, in the most contemporary meaning of the term, was conceived and implemented within the framework of nation-states.

A systematic differentiation of these forms of spatiality will be carried out after more illustrations of this question from other authors who have the most contributed to shaping the concept of the social imaginary, as I mean it, and mobilized this spatial dimension. From the start of his book on the subject (2005), Michael Warner, sets out, in the specific attention that he brings to "publics" in his theory of the social imaginary, different meanings of the notion of public. He differentiates the public-audience, in other words, the public in a conference, a show or a sports event that usually assumes the co-presence of a specifically designed space, from the public of the public sphere, in other words, the community within which individuals, readers or authors interact, through the mediation of printed books and papers. His main illustration - the constitution of a public sphere in the North American British colonies in the decades preceding the American revolution - points out that the circulation of ideas that propels the emergence of this public sphere mainly mobilizes the spatiality of the diffusion of the books and newspapers by which these ideas take shape and materiality, and, secondarily, only those coming from conferences and debates, therefore, that of co-presence. Warner emphasizes the decisive role played by various forms of spatiality in his analysis of the emergence and stabilization of a public sphere: "A public is a space of discourse organized by nothing other than discourse itself." (2002, p. 50). It is a role that Jürgen Habermas' theory of public space ([1962] 1989) tended to obscure. The reference made by Warner to the concept of "print capitalism" borrowed from Anderson is an additional illustration of his spatial conception of public space.

While very different, Edward Said's thesis in Orientalism (1977) features instituting forms of spatiality, even though the expression is foreign to his vocabulary. His thesis in this book is not to provide a catalogue of the representations Westerners gave themselves to think the Orient, not even in the chapter "imaginative geographies." His aim is rather to show how these rep- 
resentations contributed to the symmetric construction of "the Orient" and "the West" but also of collectives and corresponding identities.

Not wanting yet to go too far into the chapters that follow, these forms of spatiality can nevertheless be differentiated according to their respective ontological statuses, in other words, their way of being. Because they are considered objectifiable and result from a process of objectification, some are fundamental pieces of knowledge. This is the case for Warner's public sphere spatiality for the circulation of political texts. It is also the case for the spatiality of modern cosmogonies or meta-geographies whose emergence Said analysed - the Orient (the East) and the West as macro-geographic entities shaped by Orientalism. This spatial and objectivized ontology requires the intervention of material representations. Maps, textual descriptions, mythical and religious stories, paintings and photos combine their object spatiality with a referential one of what they represent. Both of these types of spatiality are distinct but complementary of a third one, that of phenomenological experience. This eminently subjective experience is decisive in the practice of places, of course, in the co-presence and interactions between individuals, but also in the use of objectivized representations. Applied to the example of a national museum, this plurality and combination of types of spatiality show the forms that correspond to the materiality of the site and the representations that are organized around it, the entities that are objectivized in the scenography and the discourse that accompanies it (referring to territory, capital cities, places of memory, etc.), and the spatial experience of the visitor whose point of view (literal meaning) about the objects of representation (via the scenographic arrangement itself) and the point of view (figuratively) about the entities and the stories put into play one attempts to guide. One can see how the social imaginary and individual imagination are organized around this combination of objectivized and subjective types of spatiality.

This differentiation of the ontological forms and types of spatiality prepares the field for the analysis of the spatial dimension of the social imaginaries that traverse this whole book. It sketches out an intention that recalls Henri Lefebvre's at the beginning of The Production of Space ([1974] 1991), without fully sharing his theoretical bases. In light of the perceptible limits in the dominant ways, then, of invoking space in the social sciences, Lefebvre wrote:

epistemological-philosophic thinking has failed to furnish the basis for a science that has been struggling to emerge for a very long time, as witness an immense accumulation of research and publication. That science is - or would be - a science of space. To date, work in this area has produced either mere descriptions which never achieve analytical, much less theoretical, status, or else fragments and cross-sections of space. There are many reasons for thinking that descriptions and cross-sections of this kind, though they may well supply inventories of what exists 
in space, or even generate a discourse on space, cannot ever give rise to a knowledge of space. ( [1974] 1991, p. 7)

Lefebvre's ambition was to found such a science of space that integrates the plurality of its expressions:

Social space is not a thing among other things, nor a product among other products: rather subsumes things produced, and encompasses their interrelations in their coexistence and simultaneity - their (relative) order and/or (relative) disorder. It is the outcome of a sequence and set of operations, and thus cannot be reduced to the rank of simple object. cannot be reduced to a simple object. ... Itself the outcome of past actions, social space is what permits fresh actions to occur. ([1974] 1991, p. 73)

This book shares this observation and the attempt to provide a general perspective but it takes its own route.

\section{IN WHAT WAY IS SPACE INSTITUTING?}

The exercise of differentiation and typology of the forms of spatiality, even rudimentary at this stage, is risky: it may make the reader believe that they play a similar role in the dynamic of social imaginaries. But they don't and it is important to explain here how they differ in this, first in some previously mentioned authors' work, second in this book.

Anderson's proposal that the nation is an "imagined community" has a premise: the members who compose it "will never know most of their fellow-members" (Anderson, 1983, p. 6). From then on, the feeling of belonging to a common nation could not result from the direct interaction among the members of this nation. It is by imagination and thanks to a set of artefacts - in particular, books, maps and museums - that this feeling can come to light. In other words, individual imagination mobilized in the production of "imagined communities" is conceived by Anderson as a faculty that makes it possible to summon by thinking what is absent from the field of perception, that is, a spatial condition. The success of his concept of "imagined communities," and the fact that many authors like Taylor and Warner subscribed to it, has a lot to do with the original postulate. Then Anderson sets up a hierarchy between the forms of spatiality mobilized in his analysis. If one follows Anderson, the direct interaction among members of a nation is not a condition for the emergence of a national imaginary and even less a constitutive dimension of this imaginary. On the contrary, the circulation of printed material, museographic stagings and maps would have this constitutive characteristic. Symmetrically, this proposal, which seems to make good sense, suggests that small communities, in particular so-called "primordial villages of face-to-face contact" 
(Anderson, 1983, p. 6) and in which generalized interaction between individuals can occur, would not need to imagine themselves as such.

While it does not prevent Anderson from developing a very subtle analysis of the emergence of nationalisms, this original postulate is not compatible with the signification that this book adopts of the notions of social imaginary and individual imagination. This book has a different initial postulate: every community, regardless of its dimensions, has to be imagined to be a community. Everyone's imagination adjusts to a framing social imaginary, regardless of the size of his/her community of belonging. Furthermore, the social imaginary is particularly at work in in situ interaction practices. In a way, this is Said's point of view. The imagination at work in Orientalism is clearly that of the Europeans who imagine remotely, therefore in the absence of what "the Orient" and "the Oriental" are. But it was also the imagination at work in situ, in Cairo or in Tunis, when, equipped with the schemas of Orientalism, a traveller, Flaubert and others, came into direct contact with people from Cairo and Tunisians. In this sense, what specifies imagination is not that it fills an absence. It is the vector by which an individual connects his/her direct experiences to very varied things: abstractions, general knowledge, memory, plans for the future, etc. Only some arise from absence.

In other words, social imaginary as it is conceived of here is not what a collective that would never have direct experience in its totality can imagine. It is what frames the structuring of individual and interactive experiences, their significations and corresponding values, including prevailing direct interaction practices. This position encourages me to grant as much importance to the places and ways of direct interaction between individuals of a same "imagined community" as to the mediators (for example printed material and maps) in the dynamic of social imaginaries.

This said, the forms of corresponding spatiality are not all instituting. I distinguish those that are conditions of possibility of these imaginaries, those that are constitutive forms of them and those that are only expressive forms of them. To illustrate this distinction, I return to the aforementioned example of public space in its literal meaning, which combines what I have called several forms of spatiality. It has its own materiality, organized by its streets, squares, etc. This organization constitutes the stage and orients the form of so-called public manifestations, protest demonstrations or commemorations. The material arrangement of public space is a condition of possibility of these manifestations, one factor of their arrangement, but as such and alone it is not a constitutive form of a social imaginary. On the contrary, the manifestations themselves can be. If we incorporate Arendt's concept of space of appearance, the arrangement of space by the people who interact in the public space and construct the public debate in this arena are part of the very essence of the political. Likewise, a ceremony, for example, held in honour of a national 
hero, can be seen as a performance that performs a nation if one agrees that the nation needs to be performed in order to be. Just as instituting is the land property regime that most often prevails in the distinction between space called public and space called private. On this point also, not only is the analysis of historians of antiquity precious but also Arendt's, because these authors showed that land ownership in Greek city-states conditioned not only the social organization and the status of citizenship but also the spatial distribution of the constitutive activities of social and political life. Moreover, manifestations in public space sometimes invoke other spaces: the popular gatherings during the French revolution because of the threat of the European coalition and of the liberation of Paris in 1944 invoked spatial entities, particularly the French territory, and are as many instituting referents of the national imaginary to which these gatherings marked a collective attachment, in an expressive mode.

\section{CONSTITUTIVE SPATIALITY OF SOCIAL IMAGINARIES}

Without neglecting either spatiality as a condition of possibility of a social imaginary or that of its expressive forms, it is especially the constitutive spatiality of social imaginaries that this book addresses. If, as I suggest, social imaginaries are instituting, then some specific forms of spatiality are part of this institutionalization as such.

What are the conditions for a space to be instituting? It is instituting if it constitutes a fundamental component of the symbolic universe of a collective and that of its principal institutions. The symbolic universe is the totality of the references with which a collective provides itself to conceive of itself on its own, in terms of its identity and to think the collectives with which it interacts in terms of alterity. It brings about forms of self-reference by which this collective designates and qualifies its totality or its components, including individuals. It also brings about references to the exteriority of the group (for example, the earth surface, "nature," or "the others") when the modalities with which these references are invoked are put into the service of this self-representation. Spatiality is one constitutive dimension of this symbolic universe when, for example, it connects individuals to their geographic localization, to their spatial practices, or collectives to places that specify them, a state to its territory or even its capital, etc.

The institutional universe designates the institutions as a whole that a collective provides itself with to organize and regulate interactive practices among its members. It covers macro-institutions like the state as well as secondary or less important ones like money or land property. Spatiality is a constitutive dimension of this institutional universe if the space is a basic component of its organization and the social practices connected to it. 


\section{MODERNIT(Y/IES)}

Exactly which social imaginaries are involved in this book? It is those that institute modern societies, each one taken as a whole but also those of the collectives that compose them. But it goes further. The spatiality of contemporary imaginaries needs to be analysed in light of the present recomposition of collective identities and the plurality of scales - from local to global - in whose framework these recompositions belong. Lastly, these imaginaries will be studied in the function of the societies that thus produce them in an endogenous dynamic. They will also be analysed according to the relations that link them and that are sometimes power relations. A whole body of critical literature (Hobsbawm, 1990; Gellner, 1983; etc.) has emerged over the past 20 years around the idea that nations are the product of nationalisms conceived and instrumentalized by elites and modern states. In its most radical version, this literature postulates, even if it is not the vocabulary used, that the state imaginary (constitutive of the State) has determined the national imaginary (constitutive of the nation). While there is much to be learned from these analyses they do not belong in this book's perspective in that they point more to the ideological dimension, in terms of Marxist theory, than the imaginary dimension, in terms of theoreticians of the social imaginary from which I take my inspiration to account for the at least partial indetermination of the corresponding social forms. Likewise, the emergence of alternatives to the stato-national frame of today's societies - globalization, regionalization and resurrection of the local - that I call post-national - does not signal the end of the national imaginary nor even necessarily the opening of a field of possibilities for these alternatives that lead more rarely to competitive imaginary forms than to related forms following an adjustment of corresponding collectives. The question of power in the constitution of social imaginaries must not be dismissed, but it must not either be caricatured, nor even linked to one, and thus reductive, form of the relations of symbolic force among collectives.

\section{FOUR CONCEPT CHAPTERS, SIX CASES AND ONE EPIPHANY}

This book is composed of four chapters mainly devoted to conceptual argumentation. Chapter 2 details the book's thesis concerning the instituting character of the spatiality of modern social imaginaries. It also goes into detail about the differentiation of the forms of spatiality minimally introduced so far. Taking the most ordinary activities - a football match, a financial transaction, a street manifestation, etc. - it attempts to show how the spatiality of these 
practices that all require individuals' imagining skills can be constitutive of a social imaginary.

Chapter 4 deals primarily with state imaginary. Capitalizing on the ample production of historians, philosophers and political scientists, this chapter shows how certain forms of spatiality are constitutive of the public imaginaries of modernity that appeared in Western Europe as of the sixteenth century.

Chapter 7 addresses the national imaginary. Even if there is a tendency to think the nation-state as a whole, in particular as of the French and American revolutions, the features and the dynamic of the national imaginary have to be differentiated from those of the state imaginary. Its specificity lies in the very special manifestations seen in the ways individuals conceive together, in particular in an intersubjective way, the singularity of the nation based on ordinary practices, beliefs and places that are connected to them.

Chapter 9 concerns the transformations observable today in "post-national" imaginaries as a whole. As I said a few paragraphs earlier, it is not so much a question of postulating, with this phrase, the recent emergence of imaginaries that supposedly undermine state or national imaginaries as of observing how, after decades in which these same imaginaries have sought to subsume many social forms, new forms have emerged out of original scalar combinations and interfere with state imaginary to contest its monopoly.

There is no question of competing with the works of historians or anthropologists in these chapters, especially concerning the depth of analysis and the mobilization of sources. My chapters draw on these works to sketch out a perspective of transversal analysis on the question of instituting forms of spatiality alone. Each of these "concepts" could merit a book in itself; they must be understood as an invitation to deepen the path laid out, with the help of the references mentioned.

In the meantime, six cases wend their way into the whole. They bring as many contextualized illustrations to the four conceptual chapters that constitute the backbone of the book. To the concepts addressing the question dealt with in this book in an essentially generic way, these cases will add an empiric complement, with tangible examples showing imagination and imaginary at work in the constitution of particular social forms.

A first case (Chapter 3) illustrates the concept of social imaginary itself by showing how the constitution of one of the first national parks in history, Yosemite, in California, pertains to the adoption of social imaginaries of nature and conceptions of its spatiality in the second half of the nineteenth century. The next two cases (Chapters 5 and 6) illuminate the general sense of the second conceptual chapter (Chapter 4) devoted to state imaginary, focusing on cartographic production in Tudor and Stuart England and in colonial Indochina. The national imaginary concept (Chapter 7) will be completed by a case devoted to the production and practice of symbolic places of the nation 
in France and in the United States (Chapter 8). Finally, the last two cases (Chapters 10 and 11) consider two manifestations of the post-national imaginary in the United States: first the transformation of Little Italy, a New York City neighbourhood, between 1970 and 2010, when New York City started to conceive its identity in terms of cosmopolitanism; then the upsurge in alternative communities in California in the 1960s to the 1990s, that invented new scales of reference to nature and instituted themselves accordingly.

This collection of concepts and cases can be read in several manners: in a linear way to follow the terms of the argument, selectively, and in the hope that each of the chapters is self-explanatory, or randomly, as the reader so desires. 